\title{
Research Supplements to Promote the Recruitment of Individuals with Disabilities
}

National Cancer Institute

\section{Source}

National Cancer Institute. Research Supplements to Promote the Recruitment of Individuals with Disabilities. NCI Thesaurus. Code C19008.

The National Institutes of Health $(\mathrm{NIH})$ and its awarding components have developed this initiative to extend opportunities to individuals with qualifying disabilities who are capable of entering or resuming research careers. Under this initiative, individuals with disabilities are encouraged to pursue biomedical research careers in areas within the mission of an NIH awarding component through supplemental awards to certain ongoing research grants. It is hoped that the plan to provide funding at several different stages in a research career will substantially increase the number of individuals with disabilities in biomedical research. 